\title{
Ferrous Alloys Research: The Iron-Oxygen Equilibrium.
}

$A^{T}$ the autumn meeting of the Iron and Steel A Institute held in September at the British Empire Exhibition, Wembley, an account was given by Dr. Rosenhain and some of his colleagues of an investigation of the alloys of iron which was begun by them rather more than a year ago under the auspices of the Ferrous Alloys Research Committee, which is the successor of the Alloys Research Committee of the Institution of Mechanical Engineers. The new Committee contains representatives of the Royal Society, the Institutions of Civil Engineers, Mechanical Engineers, Electrical Engineers, Naval Architects, and Mining and Metallurgy, and the Iron and Steel Institute. Under the auspices of this Committee, and with the concurrence of the Advisory Council of the Department of Scientific and Industrial Research, a beginning has been made upon a programme of work which is more ambitious, more difficult, and more expensive than anything which has hitherto been attempted. As Dr. Rosenhain points out in his introduction (Part I.) to the research, in spite of the large amount of scientific research devoted to the alloys of iron, much fundamental knowledge as to the constitution of the binary systems is still lacking. Most of the alloys hitherto investigated contain some carbon in addition to the special alloying metal, and this may, and probably does, have a profound influence on the equilibrium in question. Many of the most important industrial alloys contain three or more elements, and their composition has heen arrived at largely by empirical methods. The precise influence of any particular element is largely a matter of guess-work. For this reason it is eminently desirable that the equilibria of the binary systems should be determined with the purest materials and the highest accuracy possible.

Messrs. Tritton and Hanson are responsible for Part II. of the research, which deals with the equilibrium of iron and oxygen, and a brief survey of their experiments will show something of the difficulties encountered in investigations complying with the above-mentioned standard. The iron was prepared by the method of Cain, Schramm, and Cleaves from an electrolyte containing pure ferrous chloride and sodium chloride. The product was satisfactorily pure except for a rather high oxygen content, due, so the authors think, to the formation of rust in the iron, which was deposited in a slightly porous form. Special attempts were made to prepare iron free from oxygen. At a later stage of the investigation a high-frequency Ajax-Northrup induction furnace became available, and the authors melted electrolytic iron previousiy purified by heating in hydrogen to $1200^{\circ} \mathrm{C}$. in a vacuum of about $2 \mathrm{~mm}$. of mercury, but the metal was not free from oxide. After various attempts, the best method was found to be to blow purified hydrogen on the surface of the metal during melting and for a period of fifteen minutes when molten. Even then the resulting metal was found to contain an amount of oxide estimated to represent about 0.08 per cent. oxygen. Both china clay and magnesia pots were used. It is to be gathered from the authors' paper that no iron prepared by them contained less than the abovementioned amount of oxygen.

One of the greatest difficulties was to obtain pots and other refractory articles suitable for the work. Those made either of silica, china clay, or alundum will not hold molten iron containing much oxide for more than a few minutes, owing to the rapid attack on the pot by the oxide. Special pots had therefore to be manufactured at the laboratory, and a new method has been developed, involving direct fusion of the refractory in an electric arc, for producing pots having internally glazed surfaces of great resistance to chemical attack. The refractory (previously melted and powdered) is placed in a suitable receptacle and spun in an electric arc in such a way as to form in a few minutes a well-shaped pot having a body of highly fired material, the internal surface of which has been completely molten, leaving a glazed surface on the interior of the pot. Only in these was it found possible to hold molten iron and iron oxide at the same time. For low-oxygen melts, china clay pots were used, while for the higher oxygen alloys, bonded pots of fused magnesia were found best.

Another difficulty which had to be overcome was

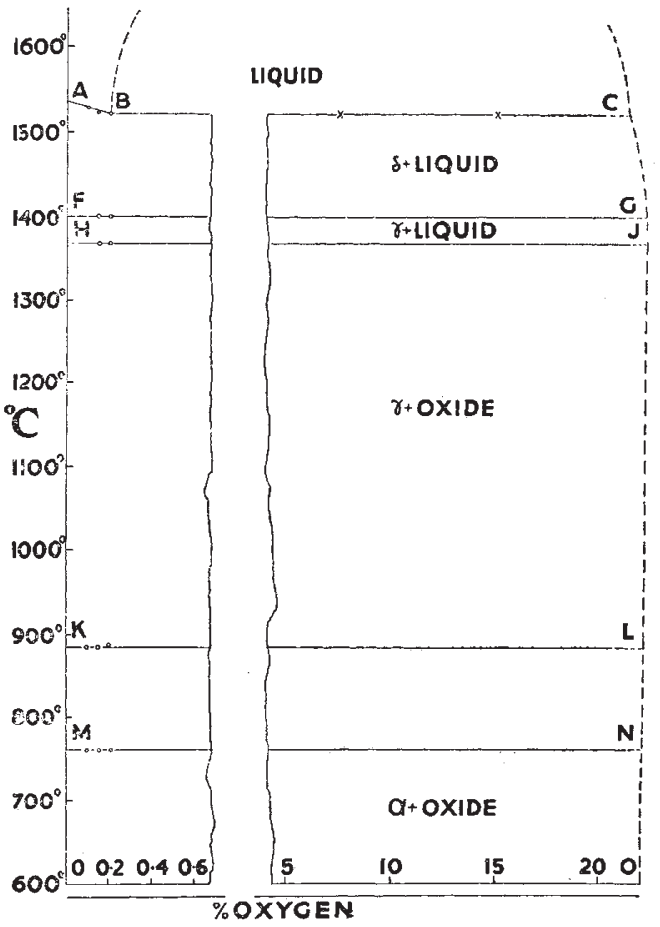

FIG. I.-Iron-oxygen equilibrium diagram.

the contamination of the thermocouples, due apparently to the penetration of the couple protector by the iron vapour. The best method was found to be to use a very low-sided pot and to blow nitrogen across the surface of the melt. Contamination was worse in the pure platinum wire than in the platinum so per cent. rhodium alloy. Accordingly the authors substituted thermocouples of wires containing 5 per cent. and 20 per cent. of rhodium, which gave a sufficient sensitivity for thermocouple work.

In spite of these improvements a certain amount of contamination always occurred, so that the couple needed frequent testing and the removal of the contaminated portions of the wire. The freezing-point of iron of the lowest oxygen content was found to be $\mathrm{I} 535^{\circ} \mathrm{C}$. referred to $\mathrm{I} 555^{\circ} \mathrm{C}$. as the melting-point of palladium. This is probably a very close approach to the freezing-point of pure iron, since, in spite of the presence of oxygen, the slight slope of the liquidus

No. 2867 , VOL. I 14$]$ 
curve of the iron-oxygen diagram indicates that the effect of this amount of oxygen must be small. The melting-point of the oxide stable at these temperatures was found to be $1370^{\circ} \mathrm{C}$., and that of the $\delta$ change point in iron $1407^{\circ} \mathrm{C}$.

The authors have given the iron-oxygen equilibrium diagram between $\mathrm{O} \cdot \mathrm{I}$ per cent. and 22 per cent. of oxygen, represented by the compound FeO. This diagram, which is reproduced in Fig. I, is of considerable interest. It shows that the percentage of oxygen dissolved by iron in the liquid state does not exceed 0.2 I per cent., and that above this the liquid separates into two melts. The lowering of the freezing-point of iron is, in fact, only about $8^{\circ}$. The solid solubility of oxygen has not been exactly determined, but is estimated to be about 0.05 per cent. It will be seen from the diagram that oxygen is practically without effect on the $\delta, \gamma$, and a change points.

The authors have been able to prepare ingots of pure iron-oxygen alloys, to roll them, and to subject them to various physical tests. The maximum weight of ingot was about $45^{\circ} \mathrm{gm}$. They have found that the low-oxygen iron ( 0.08 per cent.) can be rolled perfectly easily both hot and cold, and that the rolled material is ductile in a tensile test. It is, however, very brittle under notched bar impact tests; this may be due to the large grain size of the material which is facilitated by the purity of the metal in other respects. Ordinary normalising methods do not produce a small grain size in lowoxygen iron. With increasing oxide content there is a marked decrease in ductility. The authors have also carburised and case-hardened samples of iron of low and high oxygen contents, and have found that this can be done without difficulty. They conclude that the oxide particles appear to be practically unaffected by the process. This is certainly a matter of some importance.

Part III. of the research is contributed by $\mathrm{Mr}$. Rooney, and deals with the estimation of oxygen in "pure iron." He has found that the best temperature for complete reduction of the oxide by hydrogen is between II $50^{\circ}$ and $I 200^{\circ} \mathrm{C}$., and suggests that the problem of reducing it depends not so much on the facility with which the hydrogen can penetrate into the metal as on the ease with which the water-vapour formed can escape. Another method used is that described by Oberhoffer and Keil, which consists in heating millings with a proportion of an alloy of antimony (40 per cent.) and tin (6o per cent.), and collecting and weighing the water-vapour produced in the ordinary way. These two methods gave substantially identical results.
H. C. H. C.

\section{Seasonal Changes in Shell-fish.}

$\mathrm{M}$ . H. MUNRO FOX, in a paper published in the Proceedings of the Roval Society (B, No. 67I) in January last, entitled "Lunar Periodicity in Reproduction," refers to vol. ii. of the Philosophical Transactions, published March I667, by Henry Oldenburg, Sec.R.S., wherein, at p. 4I9, may be found the following question, forming one of a series comprised under the heading, "Inquiries for Suratte, and other parts of the East-Indies "- "Whether those shellfishes, that are in these parts plump and in season at the Full Moon, and lean and out of season at the New, are found to have contrary Constitutions in the East-Indies."

Modern zoology, through Mr. Fox, has answered this old-time question in detail; but there are some considerations that may be suitably advanced. As is well known, in the earliest years of the Royal Society, the promotion of knowledge by means of a "correspondency" with diligent persons in various parts of the world was encouraged in every possible way. Lists of inquiries were drawn up by fellows of the Society, who were severally charged with the task of reporting such information as could be secured, or see that it was communicated to Oldenburg. That zealous officer, with the prevision for which he was famous, took care that such inquiries should be placed on record in the Transactions, irrespective of replies. He desired to have "confirmations of the truth of these things from several hands before they be relyed on."

As regards the particular question which engaged Mr. Fox's attention, it would appear that it was answered-though in the briefest fashion-by the person to whom the whole body of inquiries was addressed, none other than Sir Philiberto Vernatti, then resident in Batavia. Sprat's "History of the Royal Society" was published in 1667 , and in this he prints the "inquiries" for the East Indies, but goes further than Oldenburg, inasmuch as he supplies the original answers. It is matter for conjecture how it came about that Oldenburg only furnished the questions, whilst Sprat gave these, supplemented by the replies. The reply respecting shell-fishes was, "I find it soe here by Experience at Batavia, in oysters and crabs."

It is interesting to record the origin of the East India inquiries. So early as I664, Vernatti had sent over a wooden case containing an "East-India present." The case was opened at a meeting of the Society, and at the same time the answers returned by Vernatti to inquiries which he had previously received (recommended to him by Sir Robert Moray), were read and ordered to be registered. Further, Moray was desired to write a letter of thanks for the double gift, and to take care that an order be drawn up for moving the East India Company by favour of the Lord Berkeley, that they would please to recommend such kind of inquiries to their correspondents in the East Indies, and take care of the conveyance of what should be committed to them for the Society.

Afterwards, Dr. Wilkins was desired to speak to his lordship, that he would, in the name of the Royal Society, move the committee of the Company to give their interest. Wilkins reported later that the Lord Berkeley had spoken with several of the Company and certain "very inquisitive men, now in town," who were thought able to answer queries. If unable, these queries would be put before their resident factors. Whereupon, Dr. Wilkins, Dr. Croune, and $\mathrm{Mr}$. Colwall were charged with the prosecution of the matter. As an issue, towards the end of the year Dr. Wilkins acquainted the Society that some of the East India Company were ready to attend them, and it was ordered that the president (Viscount Brouncker), and as many of the committee for correspondence as conveniently could, should give them a meeting forthwith at some place to be agreed upon. Following these engagements, we hear no more of the undertakings until the vear 1667 .

In general connexion with the foregoing, it may be mentioned that in the Philosophical Transactions for $I 669$ a paper is printed entitled "On the odd turn of certain snails contrary to the solar turn." 